\title{
Cumulative oxygen deficit is a novel biomarker for the timing of invasive mechanical ventilation in COVID-19 patients with respiratory distress: a time- dependent propensity score analysis
}

\section{Huiqing Ge}

Zhejiang University School of Medicine

Jiancang Zhou

Zhejiang University School of Medicine

\section{Fangfang LV}

Zhejiang University School of Medicine

Junli Zhang

Zhejiang University School of Medicine

Jun Yi

Jingmen first people's Hospital

Changming Yang

The First People's of Hospital of Jingmen City

Lingwei Zhang

Zhejiang University of Technology

Yuhan Zhou

Zhejiang University of Technology

Qing Pan

Zhejiang University of Technology

Zhongheng Zhang ( $\nabla$ zh_zhang1984@zju.edu.cn )

Zhejiang University School of Medicine

\section{Research Article}

Keywords: covid-19, mortality, mechanical ventilation

Posted Date: July 16th, 2020

DOl: https://doi.org/10.21203/rs.3.rs-42597/v1

License: (c) (i) This work is licensed under a Creative Commons Attribution 4.0 International License.

Read Full License 
Page $2 / 19$ 


\section{Abstract}

Background and objectives: The timing of invasive mechanical ventilation (IMV) is controversial in COVID-19 patients with acute respiratory hypoxemia. The study aimed to develop a novel biomarker called cumulative oxygen deficit (COD) for the initiation of IMV.

Methods: The study was conducted in four designated hospitals for treating COVID-19 patients in Jingmen, Wuhan, from January to March 2020. COD was defined to account for both the magnitude and duration of hypoxemia. A higher value of COD indicated more oxygen deficit. The predictive performance of COD was calculated in multivariable Cox regression models. Time-dependent propensity score matching was performed to explore the effectiveness of IMV versus other non-invasive respiratory supports on survival outcome.

Results: A number of 111 patients including 80 in the non-IMV group and 31 in the IMV group were included. Patients with IMV had significantly lower $\mathrm{PaO}_{2}(62(49,89)$ vs. $90.5(68,125.25) \mathrm{mmHg} ; \mathrm{p}<$ $0.001)$, and higher COD $(-6.87(-29.36,52.38)$ vs. $-231.68(-1040.78,119.83))$ than patients without IMV. As compared to patients with COD $<0$, patients with COD $>30$ had higher risk of fatality (HR: $3.79,95 \%$ Cl: 2.57 to $16.93 ; p=0.037)$, and those with COD > 50 were 10 times more likely to die (HR: $10.45,95 \% \mathrm{Cl}$ : 1.28 to $85.37 ; p=0.029)$. The Cox regression model performed in the time-dependent propensity score matched cohort showed that IMV was associated with half of the hazard of death than those without IMV (HR: $0.56 ; 95 \% \mathrm{Cl}: 0.16$ to $1.93 ; p=0.358)$.

Conclusions: The study developed a novel biomarker COD which considered both magnitude and duration of hypoxemia, to assist the timing of IMV in patients with COVID-19. We suggest IMV should be the preferred ventilatory support once the COD reaches 30

\section{Introduction}

Coronavirus disease 2019 (COVID-19) has spread all over the world since its first outbreak in Wuhan, China in December 2019 [1,2]. The fatality rate was reported to be around $5 \%$ all over the world [3]. A substantial number of patients (19\%) infected with the severe acute respiratory syndrome coronavirus 2 (SARS-CoV-2) will develop respiratory distress and acute lung injury [4,5]. Respiratory support becomes important for this type of severe patients [6]. The surviving sepsis guideline of critically ill COVID-19 patients recommended use of oxygen supplementation to main pulse oximetry $>90 \%$, followed by noninvasive mechanical ventilation (NIV), high-flow nasal canula (HFNC), invasive mechanical ventilation (IMV) and extracorporeal membrane oxygenation (ECMO). However, there is no specific recommendations for the timing of transition from non-invasive support to IMV, and the recommendations are largely based on expert opinions. For example, the guideline recommends "close monitoring for worsening of respiratory status, and early intubation in a controlled setting if worsening occurs" [7]. This recommendation is based on best practice statement and there is no data on when IMV 
should be initiated. In clinical practice, the judgement of "worsening" is subjective and varied substantially between different institutions and physicians. It is controversial on the timing of initiation of IMV. On the one hand, IMV is able to reverse catastrophic hypoxemia and maintain tissue oxygenation, which is life-saving for COVID-19 patients with severe hypoxemia. On the other hand, IMV can cause ventilator-induced lung injury [8,9], and patients on IMV usually requires large dose of sedatives, analgesics and even neuromuscular blockades [10-12]. These drugs have significant adverse effects $[13,14]$. Thus, it is difficult to determine the timing of IMV due to lack of evidence.

In our experience, we proposed that the timing of transition from non-invasive oxygenation to IMV should consider both the magnitude of hypoxemia and the duration of the hypoxemia. Thus, we developed a novel marker called Cumulative Oxygen Deficit (COD) to reflect both dimensions. By using a single biomarker, we reduce a two-dimension feature to a one-dimension parameter that is comparable between different patients. In our study, we hypothesized that the COD before IMV could be a better biomarker than $\mathrm{PaO} 2$ to predict survival outcome. Furthermore, we explored whether IMV was more effective to reduce mortality than other non-invasive ventilatory supports for patients with respiratory distress by using time-dependent propensity score matching.

\section{Methods}

\section{Study design and setting}

The study was conducted in four designated hospitals for treating COVID-19 patients in Jingmen, Wuhan, from January to March 2020. Medical records were retrospectively reviewed to identify variables and eligible patients. Laboratory tests and type of ventilation support were recorded as longitudinal data. The study was designed as a longitudinal study that all patients were followed until hospital discharge. One subject contributed several observation units. Patients were divided into those with IMV and those without IMV during hospitalization. Time-dependent propensity score was employed to explore potential causal effect of IMV on survival outcome. The study was approved by the ethics committee of the First People's hospital of Jingmen (Approval number: 202002007) and the ethics committee of Sir Run Run Shaw hospital (20200407-32). Individual patient data were de-identified before analysis. Informed consent was waived as determined by the IRB due to retrospective nature of the study design. All methods were carried out in accordance with relevant guidelines and regulations.

\section{Study population}

COVID-19 was confirmed by either 1) genetic sequencing showed highly homogenous sequence with the known novel coronavirus; or 2) novel coronavirus nucleic acid was positive as confirmed by real time (RT)-PCT in respiratory or blood specimen [7,15]. All patients with respiratory distress with one of the following criteria were eligible: respiratory rate $>30 / \mathrm{min}$, or oxygen saturation $\leq 93 \%$, or $\mathrm{PaO} 2 / \mathrm{FiO} 2$ ratio $\leq 300 \mathrm{mmHg}$. We screened medical records on admission and identified patients with pulse oximetry < $92 \%$ on room air and requires oxygen therapy (OT). Exclusion criteria included: 1) patients with chronic 
obstructive pulmonary disease with baseline pulse oximetry < $92 \%$; 2) pregnant women; 3) subjects younger than 18 years old; 4) patients with do-not-resuscitate order; and 5) patients with comorbidities such as severe burn, recent major stroke with paralysis, terminally ill malignancy, immuodeficiency and dialysis-dependent renal failure.

\section{Clinical variables}

Demographics such as age and sex were recorded. Comorbidities of respiratory system, cardiovascular system and smoking history were extracted from the medical records. All laboratory variables were recorded in a longitudinal manner. These included serum lactate, arterial partial oxygen pressure $\left(\mathrm{PaO}_{2}\right)$, arterial partial pressure of carbon dioxide $\left(\mathrm{PaCO}_{2}\right)$, base excess $(\mathrm{BE}), \mathrm{pH}, \mathrm{C}$-reactive protein (CRP), Lymphocyte count, and fraction of inspired oxygenation (FiO2) were extracted.

Respiratory support included OT, NIV, HFNC, IMV and ECMO. The transition time from one type to another was recorded to create a number of time intervals at which a subject was on a specific type of respiratory support. Laboratory variables were then matched to each time interval by their respective measurement time. This created a dataset of counting process that included the start time and end time for an interval.

Clinical outcomes included vital status at hospital discharge, length of stay in the hospital were recorded.

\section{Calculation of cumulative oxygen deficit (COD)}

For patients with IMV, COD was calculated before the use of IMV. Figure 1 is a sample patient used to illustrate the calculation of COD:

$\operatorname{COD}(\mathrm{mmHg} \cdot$ day $)=80 \times\left(t_{5}-t_{1}\right)-\sum_{i=1}^{4}\left(x_{i+1}+x_{i}\right) \cdot\left(t_{i+1}-t_{i}\right) / 2$,

where $x_{i}$ is the value of $\mathrm{PaO}_{2}$ measured in $\mathrm{mmHg}$, and ti is the time at which $x i$ is measured. The reference $\mathrm{PaO}_{2}$ was $80 \mathrm{mmHg}$ because the oxygen saturation will not continue to rise above this reference value [16]. Thus, the COD accounted for both magnitude and duration of hypoxemia before IMV. We hypothesized that the longer a patient was on hypoxemia before IMV, the worse of the survival outcome. On the other hand, the outcome would be not so bad if hypoxemia was immediately corrected with IMV even if the magnitude of hypoxemia is large.

\section{Statistical analysis}

Demographic and laboratory data were compared between patients with and without IMV. Normal data were expressed as mean and standard deviation and were compared between groups with $t$ test. Skewed (non-normal) data were expressed as median and interquartile range (IQR) and were compared with rank- 
sum test. Categorial variables were expressed as the number and percentage and were compared using Chi-square or Fisher's exact test if appropriate [17].

Alluvium plot was employed to visualize how patients transitioned from different types of respiratory support. In patients with IMV, we created multivariable Cox regression model to explore the independent predictors of survival outcome. The COD was categorized into four categories at cutoff values of 0,30 and $50 \mathrm{mmHg} \cdot$ day. A COD value of $30 \mathrm{mmHg} \cdot$ day is equivalent to $60 \mathrm{mmHg}$ for 1.5 days, and a negative value indicates no oxygen deficit. Other variables such as time from admission to IMV, $\mathrm{PaO}_{2}, \mathrm{PaCO}_{2}$, Lactate, lymphocyte count, CRP and BE were adjusted for in the model. The predictive performance of COD was compared with $\mathrm{PaO} 2$ before intubation and the time from admission to intubation. We reported time-dependent AUC for the discriminations from day 7 to 28 after hospital admission [18].

Time-dependent propensity score matching was used to account for the differences between patients with and without IMV during hospitalization. We divided the maximum follow-up time into 4 strata from 1

to 4. Propensity score was calculated as the probability of receiving IMV at a certain time stratum. The probability was the cumulative hazard estimated from a Cox model regressing the use of IMV on predictors. The matching process started at stratum 1 all the way to stratum 4 . A control patient who had been matched would be deleted from latter matching. The control group was defined as those who had no yet received IMV on and before a stratum. Thus, a patient who received IMV in stratum 4 could be a control and be matched to an IMV patient in stratum 1. Time-dependent propensity score matching was employed to account for immortal time bias that a patient who lived longer can have more chances to receive IMV [19-21].

All statistical analyses were performed using RStudio (Version 1.1.463). Two-tailed $p$ value less than 0.05 was considered as significant.

\section{Results}

\section{Study population}

A total of 111 patients met the inclusion criteria and were included for analysis. There was no patient being excluded from the participating hospitals. There were 80 patients did not need IMV, and 31 patients required IMV during hospitalization. Patients with IMV had significantly lower $\mathrm{PaO}_{2}(62(49,89)$ vs. 90.5 $(68,125.25) \mathrm{mmHg} ; \mathrm{p}<0.001)$, higher $\mathrm{pH}(7.44(7.38,7.47)$ vs. $7.40(7.35,7.43) ; \mathrm{p}=0.006)$, higher serum lactate $(2.5(1.7,3.1)$ vs. $1.7(1.1,2.85) \mathrm{mmol} / \mathrm{L}, \mathrm{p}<0.036)$ and higher COD $(-6.87(-29.36,52.38)$ vs. $231.68(-1040.78,119.83) \mathrm{mmHg} \cdot$ day) than patients without IMV during hospitalization (Table 1). The time courses of the transition from different types of respiratory support are shown in Figure 2.

\section{Independent association of COD and survival outcome in IMV patients}


COD was independently associated with survival outcome in multivariable Cox regression model. As compared to patients with COD $<0$, patients with COD from 0 to $30 \mathrm{mmHg} \cdot$ day was not more likely to die, whereas those with COD $>30 \mathrm{mmHg} \cdot$ day had higher risk of fatality (HR: 3.79, 95\% Cl: 2.57 to 16.93; $\mathrm{p}=$ 0.037), and those with COD > $50 \mathrm{mmHg} \cdot$ day were 10 times more likely to die (HR: $10.45,95 \%$ Cl: 1.28 to 85.37; $\mathrm{p}=0.029$ ). The time from admission to intubation, $\mathrm{PaO} 2$ and lymphocyte count were not associated with survival outcome (Table 2). The time-dependent AUCs of COD, PaO2 and the time from admission to intubation are shown in Figure 3. It showed that COD had consistently higher AUCs from day 14 to 21 .

\section{Time-dependent propensity score matching}

To account for the difference between IMV and non-IMV groups, time-dependent propensity score matching was employed. Factors associated with the use of IMV included PaO2 (HR for $10 \mathrm{mmHg}$ increase: $0.91 ; 95 \% \mathrm{Cl}: 0.84$ to $0.99 ; \mathrm{p}=0.022$ ), Lymphocyte count (HR: $0.27 ; 95 \% \mathrm{Cl}: 0.09$ to $0.81 ; \mathrm{p}=$ 0.020 ) and lactate (HR: $1.56 ; 95 \% \mathrm{Cl}: 1.17$ to $2.08 ; \mathrm{p}=0.003$, Table 3). After propensity score matching, 52 patients were finally included for analysis. The covariates were more balanced after matching (Figure 4). The Cox regression model performed in the matched cohort showed that IMV was associated with half of the hazard than those without IMV (HR: $0.56 ; 95 \%$ Cl: 0.16 to $1.93 ; p=0.358)$.

\section{Discussion}

The study developed a novel biomarker COD which considered both magnitude and duration of hypoxemia, to assist the timing of IMV in patients with COVID-19. In patients with IMV during hospitalization, COD before intubation was a strong predictor of survival outcome. Patients with COD > $30 \mathrm{mmHg}$-day, which is equivalent to a persistent hypoxemia with $\mathrm{PaO}_{2}$ of $60 \mathrm{mmHg}$ for 1.5 days, are more likely to die during hospitalization. The time dependent AUCs of COD were significantly higher than that of the $\mathrm{PaO}_{2}$ or the time from admission to intubation alone. Clinical implication of this finding is that we need to consider both the magnitude and duration of hypoxemia before IMV is considered. Long duration of mild hypoxemia, which is prevalent in clinical practice under NIV, may be dangerous for COVID-19 patients. The result of time-dependent propensity score matching showed that IMV was potentially beneficial for COVID-19 patients with respiratory distress, but the uncertainty is large due to limited sample size in the matched cohort. Thus, large studies are needed to confirm this finding.

Many studies have been conducted to address the question on whether NIV should be used for patients with pulmonary/direct ARDS, but the results are conflicting [22]. NIV was not associated with improved mortality or length of stay, compared with patients who were intubated without trying NIV in a cohort of Middle East Respiratory Syndrome (MERS) patients. Furthermore, most patients (92.4\%) who had tried NIV were eventually managed with IMV[23]. However, this is a retrospective study and the initiation of IMV was not standardized prospectively. The time-dependent propensity score matching analysis in our study also supports the use of IMV over other respiratory supports such as OT, NIV and HFNC. Although 
statistical significance was not reached, the large beneficial effect $(H R=0.5)$ suggests that IMV may be beneficial for survival outcome in certain group of patients. This could be explained by potential adverse effects of NIV including large tidal volumes and injurious transpulmonary pressures [24]. These adverse effects of NIV could be avoided by using IMV. For example, protective ventilation strategy can be performed with IMV $[25,26]$, but it is impossible under NIV. Furthermore, the use of NIV or HFNC can delay IMV, leading to emergency or more unstable intubations [27]. Thus, IMV should be considered as early as possible if the COD reaches $30 \mathrm{mmHg} \bullet$ day, without trying NIV or HFNC to delay intubation.

$\mathrm{PaO}_{2}$ and its derivatives such as $\mathrm{PF}$ ratio are well established risk factor for mortality outcome in patients with ARDS. Thus, PF ratio is used to classify ARDS patients into mild, moderate and severe cases [28]. However, this risk classification system considers only the magnitude of hypoxemia $[29,30]$. Our result suggest that the duration of hypoxemia can be equally important. A strength of our study is that all measurements of $\mathrm{PaO}_{2}$ were collected as longitudinal dataset, allowing for the calculation of the area under the $\mathrm{PaO}_{2}$-day curve to derive a novel biomarker. Our analysis focused on patients with IMV and found that the predictive performance of $\mathrm{COD}$ before intubation was significantly better than $\mathrm{PaO}_{2}$ or the time from admission to intubation. The latter two indices are the two components of COD. The combination of the two indices significantly improves the predictive discrimination for mechanically ventilated patients. Although direct causal inference that the use of IMV to reduce COD can improve survival outcome cannot be established with current analysis, our result identified a modifiable risk factor for survival outcome. It is reasonable to deduce that reducing COD as early as possible with IMV can be beneficial. To further explore whether reducing COD by other respiratory support such as OT, NIV and HFNC are equally effective than IMV, we performed time-dependent propensity score matching. The result showed a large beneficial effect of IMV with a HR of 0.5; however, the statistical significance was not reached probably due to the lack of statistical power.

Several limitations should be acknowledged in the study. First, the study was retrospective in design, and many unmeasured confounders may exist to influence the choice of respiratory supports [31]. The presence of such unmeasured confounders will compromise the effectiveness of the propensity score matching procedure. Second, the use of NIV or HFNC was completely at the discretion of the treating physician. There was no standard protocol in participating hospitals. Thus, it is difficult to determine whether the use of NIV or HFNC could benefits COVID-19 induced ARDS. Third, for patients without IMV, we calculated the COD across all days of hospitalization. This could be biased because the timedimension was longer than the IMV group. However, since non-IMV group generally did not have oxygen deficit across hospital stay, the COD was significantly lower than the IMV group.

\section{Conclusions}

In conclusion, the study developed a biomarker COD, which considered both magnitude and duration of hypoxemia, to assist the timing of IMV in patients with COVID-19. The effectiveness of IMV was investigated in time-dependent matched cohort and the result showed a trend of beneficial effect. We suggest IMV should be the preferred ventilatory support once the COD reaches $30 \mathrm{mmHg}$ •day. 


\section{List Of Abbreviations}

Al: asynchrony index;

WOB: work of breathing;

PEEP: positive end expiratory pressure.

DT: delayed triggering;

IEE: ineffective effort during expiration;

IQR: interquartile range.

COVID-19: coronavirus disease 2019;

PVA: patient-ventilator asynchrony;

ARDS: acute respiratory distress syndrome;

IMV: invasive mechanical ventilation.

\section{Declarations}

\section{Ethics approval and consent to participate}

The study was approved by the ethics committee of the First People's hospital of Jingmen (Approval number: 202002007) and the ethics committee of Sir Run Run Shaw hospital (20200407-32). Informed consent was waived as determined by the IRB due to retrospective nature of the study design.

\section{Consent for publication}

Not applicable

\section{Availability of data and material}

The datasets used and/or analyzed during the current study are available from the corresponding author on reasonable request.

\section{Competing interests}

None 


\section{Funding}

This research was supported by Zhejiang Provincial Natural Science Foundation of China under Grant No. LY19H010005

\section{Authors' contributions}

All authors took part in designing the study. HG, QP, and ZZ analyzed and interpreted the results and drafted the manuscript. Jiancang Zhou, FL and LZ curated data. Junli Zhang, YZ, JY and CY performed data analysis; All authors revised the manuscript critically for important intellectual content. All authors read and approved the final manuscript.

\section{Acknowledgements}

None

\section{Reference}

1. Novel Coronavirus Pneumonia Emergency Response Epidemiology Team. [The epidemiological characteristics of an outbreak of 2019 novel coronavirus diseases (COVID-19) in China]. Zhonghua Liu Xing Bing Xue Za Zhi. Chinese Medical Journals Publishing House Co., Ltd; 2020;41:145-51.

2. Wang D, Hu B, Hu C, Zhu F, Liu X, Zhang J, et al. Clinical Characteristics of 138 Hospitalized Patients With 2019 Novel Coronavirus-Infected Pneumonia in Wuhan, China. JAMA. 2020.

3. Phua J, Weng L, Ling L, Egi M, Lim C-M, Divatia JV, et al. Intensive care management of coronavirus disease 2019 (COVID-19): challenges and recommendations. Lancet Respir Med. 2020.

4. Ruan Q, Yang K, Wang W, Jiang L, Song J. Clinical predictors of mortality due to COVID-19 based on an analysis of data of 150 patients from Wuhan, China. Intensive Care Med. Springer Berlin Heidelberg; 2020;368:m641-3.

5. Wu Z, McGoogan JM. Characteristics of and Important Lessons From the Coronavirus Disease 2019 (COVID-19) Outbreak in China: Summary of a Report of 72314 Cases From the Chinese Center for Disease Control and Prevention. JAMA. 2020.

6. Yang $\mathrm{X}, \mathrm{Yu}$ Y, Xu J, Shu H, Xia J, Liu H, et al. Clinical course and outcomes of critically ill patients with SARS-CoV-2 pneumonia in Wuhan, China: a single-centered, retrospective, observational study. Lancet Respir Med. 2020.

7. Alhazzani W, Møller MH, Arabi YM, Loeb M, Gong MN, Fan E, et al. Surviving Sepsis Campaign: guidelines on the management of critically ill adults with Coronavirus Disease 2019 (COVID-19). Intensive Care Med. Springer Berlin Heidelberg; 2020;44:1691-34.

8. Herasevich V, Tsapenko M, Kojicic M, Ahmed A, Kashyap R, Venkata C, et al. Limiting ventilatorinduced lung injury through individual electronic medical record surveillance. Crit. Care Med. 
2011;39:34-9.

9. Cressoni M, Gotti M, Chiurazzi C, Massari D, Algieri I, Amini M, et al. Mechanical Power and Development of Ventilator-induced Lung Injury. Anesthesiology. 2016;124:1100-8.

10. Jakob SM, Ruokonen E, Grounds RM, Sarapohja T, Garratt C, Pocock SJ, et al. Dexmedetomidine vs midazolam or propofol for sedation during prolonged mechanical ventilation: two randomized controlled trials. JAMA. American Medical Association; 2012;307:1151-60.

11. Chang W, Sun Q, Peng F, Xie J, Qiu H, Yang Y. Validation of neuromuscular blocking agent use in acute respiratory distress syndrome: a meta-analysis of randomized trials. Crit Care. BioMed Central; 2020;24:54-8.

12. Bellani G, Laffey JG, Pham T, Fan E, Brochard L, Esteban A, et al. Epidemiology, Patterns of Care, and Mortality for Patients With Acute Respiratory Distress Syndrome in Intensive Care Units in 50 Countries. JAMA. American Medical Association; 2016;315:788-800.

13. Murray MJ, DeBlock H, Erstad B, Gray A, Jacobi J, Jordan C, et al. Clinical Practice Guidelines for Sustained Neuromuscular Blockade in the Adult Critically III Patient. Crit. Care Med. 2016;44:2079103.

14. Barr J, Fraser GL, Puntillo K, Ely EW, Gélinas C, Dasta JF, et al. Clinical practice guidelines for the management of pain, agitation, and delirium in adult patients in the intensive care unit. Crit. Care Med. 2013. pp. 263-306.

15. Jin Y-H, Cai L, Cheng Z-S, Cheng H, Deng T, Fan Y-P, et al. A rapid advice guideline for the diagnosis and treatment of 2019 novel coronavirus (2019-nCoV) infected pneumonia (standard version). Mil Med Res. 2nd ed. BioMed Central; 2020;7:4-23.

16. Collins J-A, Rudenski A, Gibson J, Howard L, O'Driscoll R. Relating oxygen partial pressure, saturation and content: the haemoglobin-oxygen dissociation curve. Breathe (Sheff). 2015;11:194-201.

17. Zhang Z, Gayle AA, Wang J, Zhang H, Cardinal-Fernández P. Comparing baseline characteristics between groups: an introduction to the CBCgrps package. Ann Transl Med. 2017;5:484-4.

18. Kamarudin AN, Cox T, Kolamunnage-Dona R. Time-dependent ROC curve analysis in medical research: current methods and applications. BMC Med Res Methodol. 2017;17:53.

19. Lévesque LE, Hanley JA, Kezouh A, Suissa S. Problem of immortal time bias in cohort studies: example using statins for preventing progression of diabetes. BMJ. 2010;340:b5087-7.

20. Lu B. Propensity score matching with time-dependent covariates. Biometrics. John Wiley \& Sons, Ltd $(10.1111) ; 2005 ; 61: 721-8$.

21. Zhang Z, Li X, Wu X, Qiu H, Shi H, AME Big-Data Clinical Trial Collaborative Group WOBO. Propensity score analysis for time-dependent exposure. Annals of Translational Medicine; Vol 8, No 5 (March 2020): Annals of Translational Medicine. 2020.

22. Chawla R, Dixit SB, Zirpe KG, Chaudhry D, Khilnani GC, Mehta Y, et al. ISCCM Guidelines for the Use of Non-invasive Ventilation in Acute Respiratory Failure in Adult ICUs. Indian J Crit Care Med. 2020;24:S61-S81. 
23. Alraddadi BM, Qushmaq I, Al-Hameed FM, Mandourah Y, Almekhlafi GA, Jose J, et al. Noninvasive ventilation in critically ill patients with the Middle East respiratory syndrome. Influenza Other Respir Viruses. 2019;13:382-90.

24. Brochard L, Lefebvre J-C, Cordioli RL, Akoumianaki E, Richard J-CM. Noninvasive ventilation for patients with hypoxemic acute respiratory failure. Semin Respir Crit Care Med. 2014;35:492-500.

25. Fan E, Brodie D, Slutsky AS. Acute Respiratory Distress Syndrome: Advances in Diagnosis and Treatment. JAMA. 2018;319:698-710.

26. Zhang Z, Hu X, Zhang X, Zhu X, Chen L, Zhu L, et al. Lung protective ventilation in patients undergoing major surgery: a systematic review incorporating a Bayesian approach. BMJ Open. 2015;5:e007473.

27. Brochard L. Mechanical ventilation: invasive versus noninvasive. Eur Respir J Suppl. European Respiratory Society; 2003;47:31s-37s.

28. ARDS Definition Task Force, Ranieri VM, Rubenfeld GD, Thompson BT, Ferguson ND, Caldwell E, et al. Acute respiratory distress syndrome: the Berlin Definition. JAMA. 2012. pp. 2526-33.

29. Dai Q, Wang S, Liu R, Wang H, Zheng J, Yu K. Risk factors for outcomes of acute respiratory distress syndrome patients: a retrospective study. J Thorac Dis. 2019;11:673-85.

30. Cartotto R, Li Z, Hanna S, Spano S, Wood D, Chung K, et al. The Acute Respiratory Distress Syndrome (ARDS) in mechanically ventilated burn patients: An analysis of risk factors, clinical features, and outcomes using the Berlin ARDS definition. Burns. 2016;42:1423-32.

31. Uddin MJ, Groenwold RHH, Ali MS, de Boer A, Roes KCB, Chowdhury MAB, et al. Methods to control for unmeasured confounding in pharmacoepidemiology: an overview. Int J Clin Pharm. 2016;38:714-23.

\section{Tables}

Table 1 Comparison between patients with and without invasive mechanical ventilation 


\begin{tabular}{|c|c|c|c|c|}
\hline Variables & Total $(n=111)$ & No IMV $(\mathrm{n}=80)$ & $\operatorname{IMV}(\mathrm{n}=31)$ & $\mathrm{p}$ \\
\hline Age, Median (IQR) & $57(45.5,68.5)$ & $56(40,67.25)$ & $64(54.5,70.5)$ & 0.076 \\
\hline Sex, male (\%) & $60(55)$ & $39(50)$ & $21(68)$ & 0.143 \\
\hline \multicolumn{5}{|l|}{ Comorbidities } \\
\hline Respiratory system, n (\%) & $18(16)$ & $13(16)$ & $5(16)$ & 1 \\
\hline $\begin{array}{l}\text { Cardiovascular system, } \mathrm{n} \\
(\%)\end{array}$ & $41(37)$ & $29(36)$ & $12(39)$ & 0.983 \\
\hline Smoking history, n (\%) & $2(2)$ & $1(1)$ & $1(3)$ & 0.482 \\
\hline $\begin{array}{l}\mathrm{PaCO} 2(\mathrm{mmHg}), \text { Median } \\
\text { (IQR) }\end{array}$ & $43(39,47.5)$ & $44(41,48)$ & $39(36,45)$ & 0.051 \\
\hline $\begin{array}{l}\mathrm{PaO} 2(\mathrm{mmHg}), \text { Median } \\
\text { (IQR) }\end{array}$ & $82(60,120)$ & $90.5(68,125.25)$ & $62(49,89)$ & $\begin{array}{l}< \\
0.001\end{array}$ \\
\hline pH, Median (IQR) & $7.42(7.35,7.44)$ & $7.40(7.35,7.43)$ & $7.44(7.38,7.47)$ & 0.006 \\
\hline $\mathrm{BE}(\mathrm{mmol} / \mathrm{l})$, Median (IQR) & $2.4(-2.05,5.1)$ & $2.35(-2.57,5.1)$ & $2.4(0.2,5.2)$ & 0.342 \\
\hline $\begin{array}{l}\text { Lactate }(\mathrm{mmol} / \mathrm{l}) \text {, Median } \\
\text { (IQR) }\end{array}$ & $1.9(1.3,3)$ & $1.7(1.1,2.85)$ & $2.5(1.7,3.1)$ & 0.036 \\
\hline PF (mmHg), Median (IQR) & $\begin{array}{l}224.32(106.14 \\
348.02)\end{array}$ & $\begin{array}{l}250.05(194.14 \\
363.64)\end{array}$ & $\begin{array}{l}111.25(71.98 \\
200.27)\end{array}$ & $<.001$ \\
\hline $\begin{array}{l}\text { CRP }(\mathrm{mg} / \mathrm{dl}), \text { Median } \\
(\mathrm{IQR})\end{array}$ & $8.9(2.75,53.2)$ & $5.5(1.78,35.83)$ & $\begin{array}{l}19.5(9.85 \\
78.05)\end{array}$ & $<.001$ \\
\hline $\begin{array}{l}\text { Lymphocyte count (), } \\
\text { Median (IQR) }\end{array}$ & $0.78(0.28,0.86)$ & $0.78(0.43,0.89)$ & $0.43(0.28,0.66)$ & 0.005 \\
\hline COD (), Median (IQR) & $\begin{array}{l}-50.38(-827.91 \\
72.67)\end{array}$ & $\begin{array}{l}-231.68(-1040.78 \\
119.83)\end{array}$ & $\begin{array}{l}-6.87(-29.36 \\
52.38)\end{array}$ & 0.018 \\
\hline COD, n (\%) & & & & $<0.001$ \\
\hline$<00$ & $56(50)$ & $49(61)$ & $7(23)$ & \\
\hline $0-300$ & $14(13)$ & $3(4)$ & $11(35)$ & \\
\hline $30-50()$ & $9(8)$ & $5(6)$ & $4(13)$ & \\
\hline$>50()$ & $32(29)$ & $23(29)$ & $9(29)$ & \\
\hline $\begin{array}{l}\text { Hospital LOS (days), } \\
\text { Mean } \pm \text { SD }\end{array}$ & $26.55 \pm 11.78$ & $26.1 \pm 11.35$ & $27.7 \pm 12.97$ & 0.548 \\
\hline Mortality, n (\%) & $22(20)$ & $13(16)$ & $9(29)$ & 0.211 \\
\hline
\end{tabular}


Abbreviations: LOS: length of stay; SD: standard deviation; COD: cumulative oxygen deficit; CRP: Creactive protein; IQR: interquartile range; $B E$ : base excess

Table 2 Multivariable Cox regression model to explore the independent association of cumulative oxygen deficit and hazard of death in patients with invasive mechanical ventilation

\begin{tabular}{|lll|}
\hline & HR $[95 \% \mathrm{Cl}]$ & $\mathrm{p}$ \\
\hline COD $(<0$ as reference) & 1 & \\
\hline $0-30$ & $1.45[0.98,3.47]$ & 0.052 \\
\hline $30-50$ & $3.79[2.57,16.93]$ & 0.037 \\
\hline$>50$ & $10.45[1.28,85.37]$ & 0.029 \\
\hline Time from admission to intubation & $0.78[0.59,1.03]$ & 0.078 \\
\hline Age & $1.20[1.00,1.44]$ & 0.056 \\
\hline Sex (female as reference) & $9.84[0.43,225.59]$ & 0.152 \\
\hline PaCO2 & $0.85[0.60,1.19]$ & 0.344 \\
\hline PaO2 & $1.00[0.97,1.03]$ & 0.939 \\
\hline pH & $0.70[0.44,1.13]$ & 0.144 \\
\hline BE & $1.89[0.70,5.08]$ & 0.206 \\
\hline CRP & $0.98[0.94,1.01]$ & 0.233 \\
\hline Lymphocyte count & $2.21[0.04,115.48]$ & 0.695 \\
\hline
\end{tabular}

Abbreviations: COD: cumulative oxygen deficit; CRP: C-reactive protein; IQR: interquartile range; BE: base excess; HR: hazard ratio; $\mathrm{Cl}$ : confidence interval

Table 3 Factors associated with use of IMV 


\begin{tabular}{|lll|}
\hline Variables & HR $[95 \% \mathrm{Cl}]$ & $\mathrm{p}$ \\
\hline $\mathrm{PaO} 2$ (for every 10-mmHg increase) & $0.91[0.84,0.99]$ & 0.022 \\
\hline PaCO2 & $1.02[0.98,1.06]$ & 0.337 \\
\hline Age & $1.02[0.99,1.04]$ & 0.235 \\
\hline $\mathrm{pH}$ (for every 0.01 increase) & $1.02[0.96,1.09]$ & 0.565 \\
\hline $\mathrm{CRP}$ & $1.00[0.99,1.01]$ & 0.824 \\
\hline Lymphocyte count & $0.27[0.09,0.81]$ & 0.020 \\
\hline Lactate & $1.56[1.17,2.08]$ & 0.003 \\
\hline
\end{tabular}

Abbreviations: CRP: C-reactive protein; HR: hazard ratio; Cl: confidence interval

\section{Figures}




\section{Sample Patient}

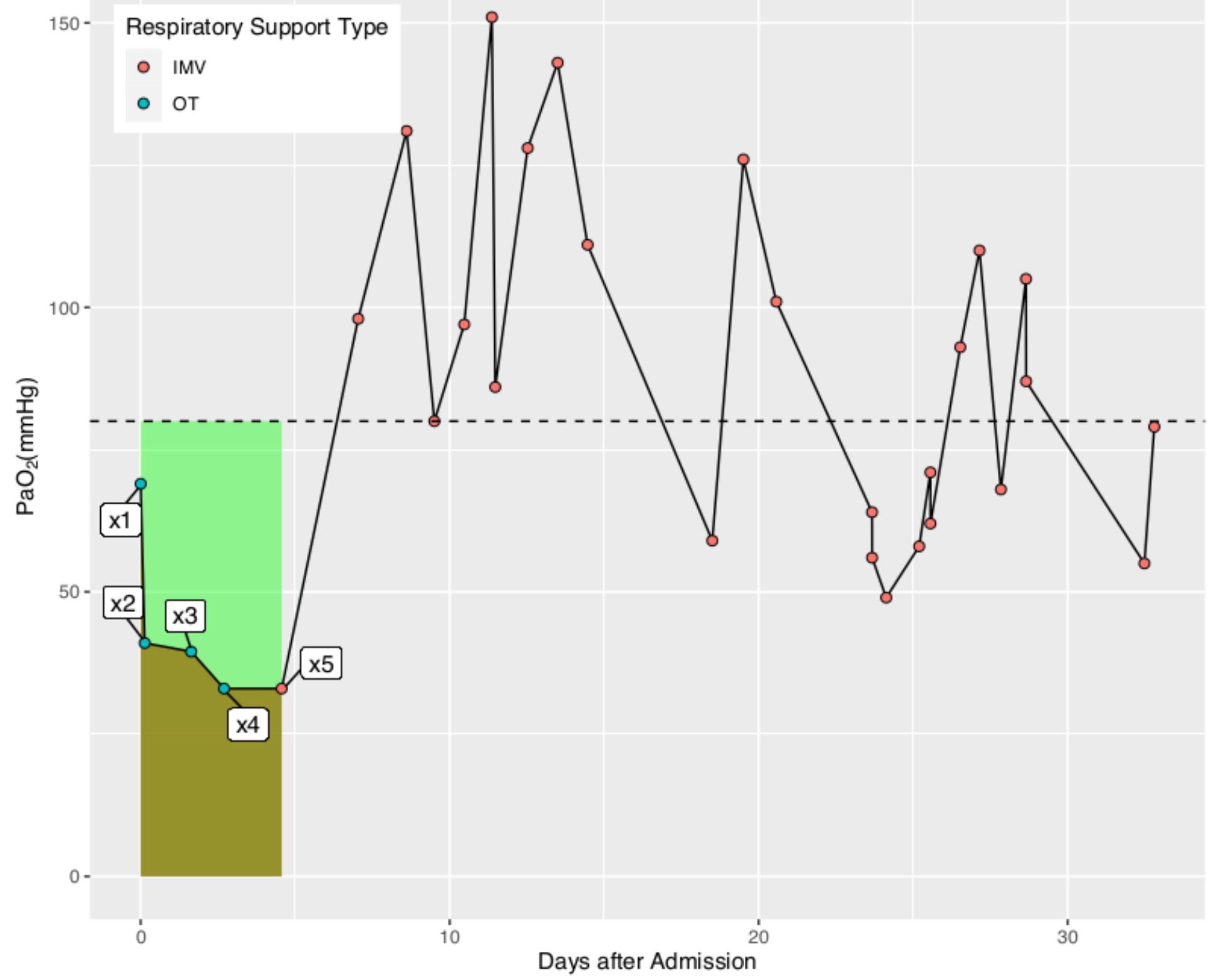

Figure 1

Schematic illustration of the Calculation of cumulative oxygen deficit (COD). The COD was calculated as the difference of the areas under the reference curve and the PaO2-day curve (the light green area in the figure). 


\section{Respiratory Support Over Time}

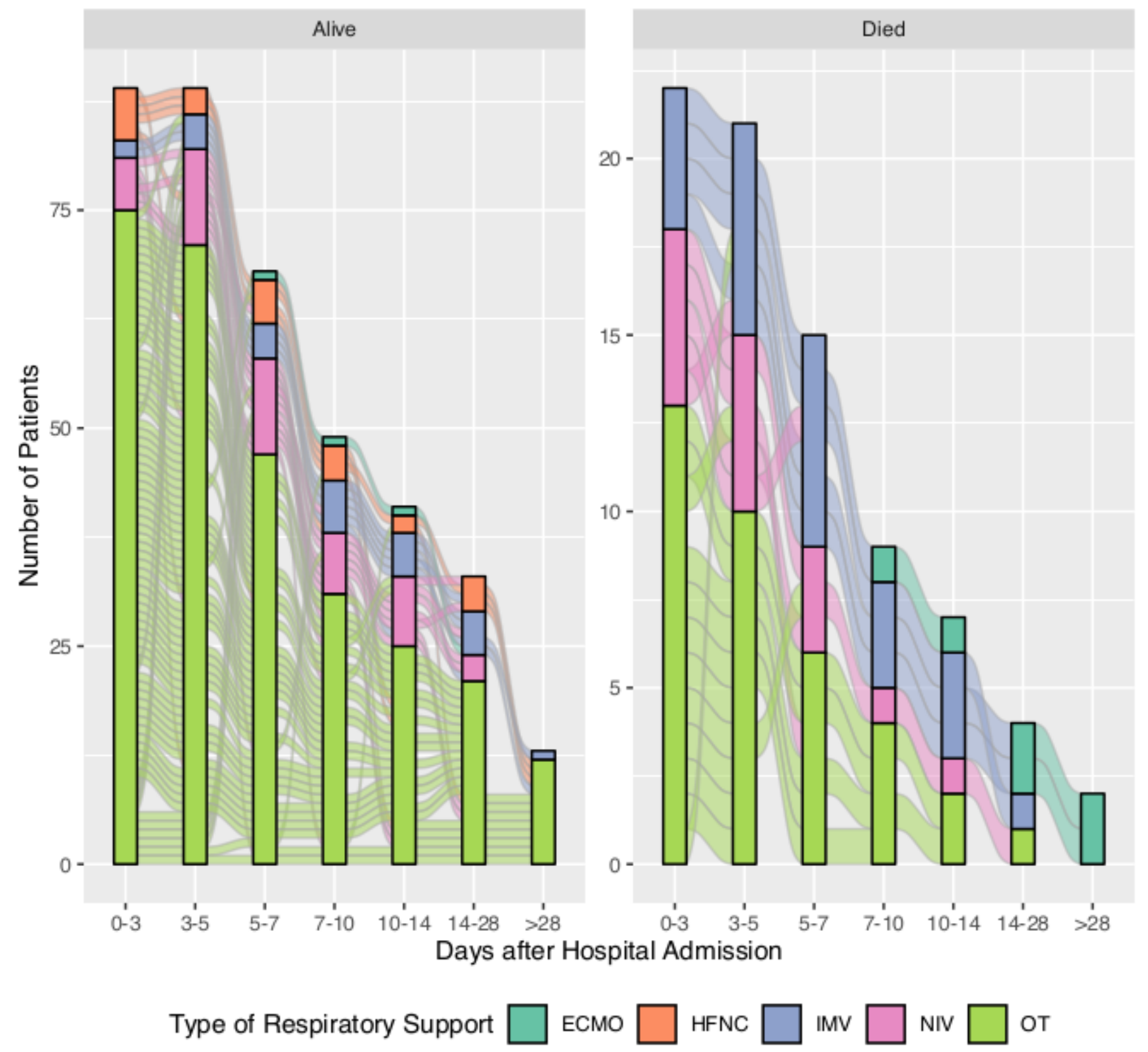

Figure 2

Alluvium plot showing the transitions of respiratory supports over time. 


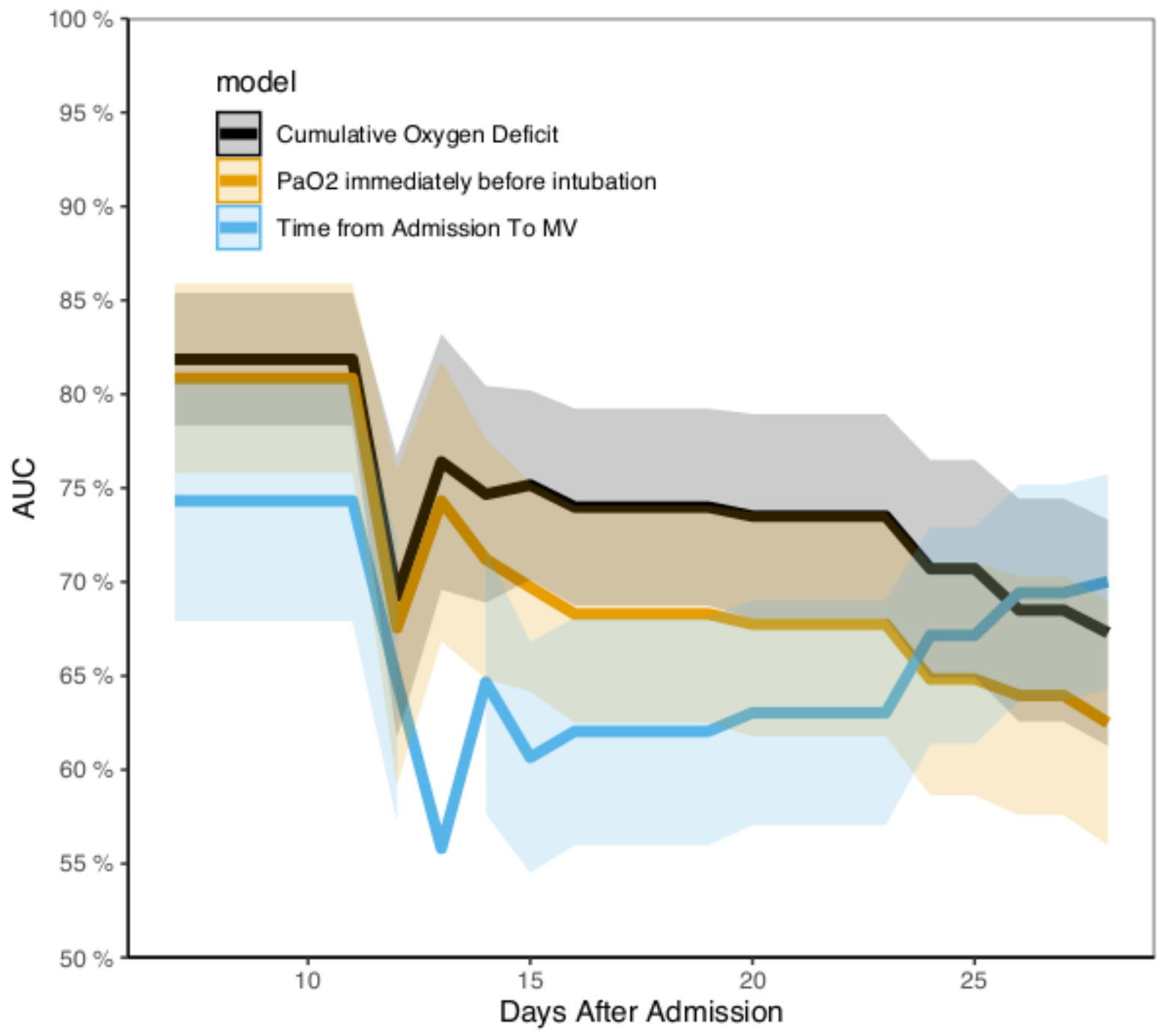

Figure 3

Time-dependent AUCs for cumulative oxygen deficit, $\mathrm{PaO} 2$ and the time from admission to intubation. The AUC of cumulative oxygen deficit was significantly higher than the other two indices from day 14 to 24. 

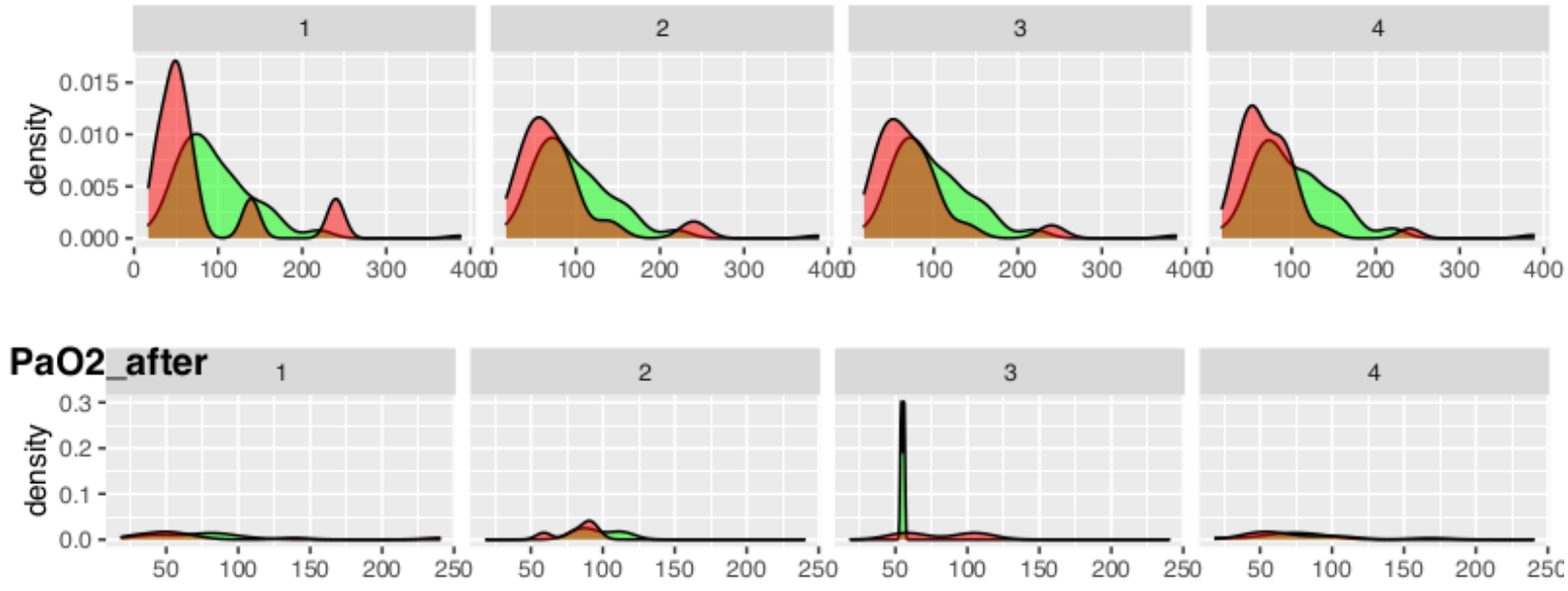

\section{Lactate_before 1}
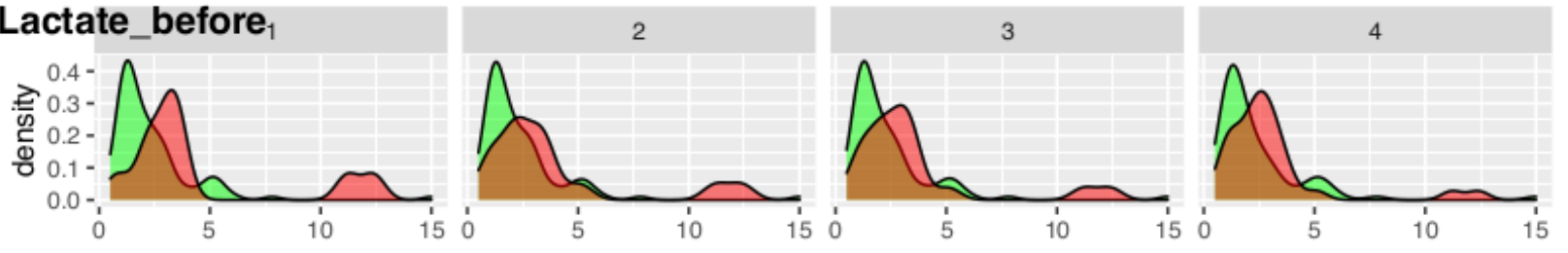

\section{Lactate_after 1}

2
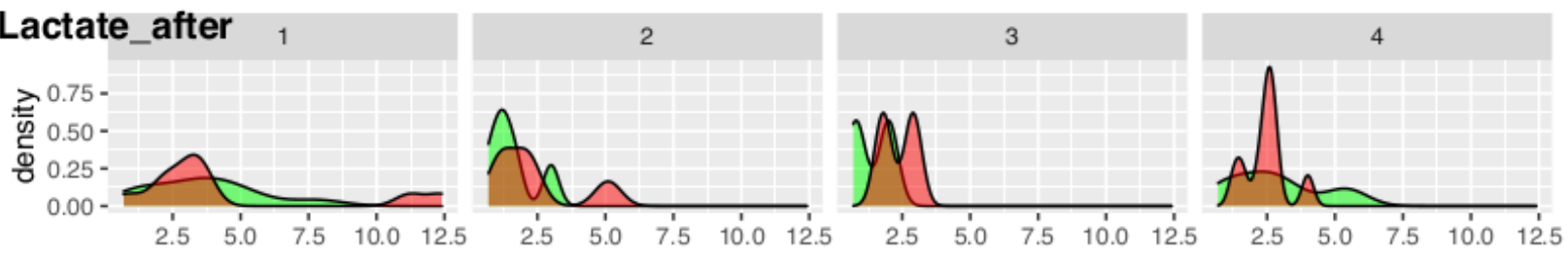

\section{Lymph_before ${ }_{1}$}
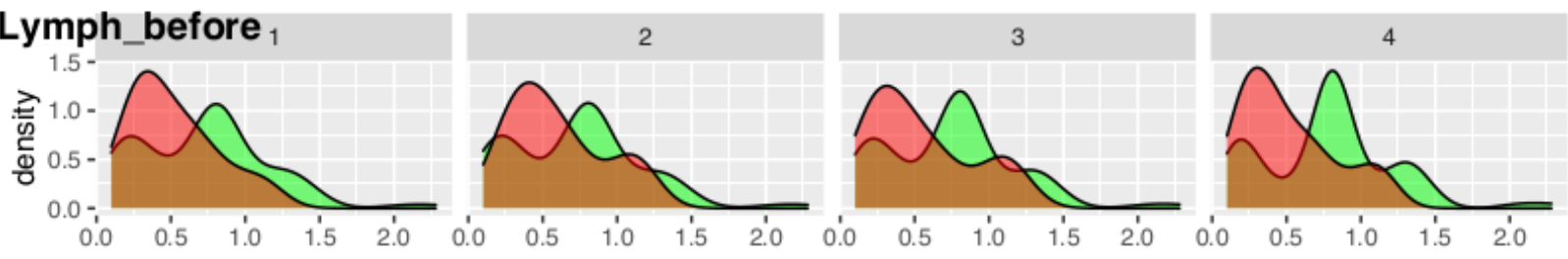

\section{Lymph_after}

2
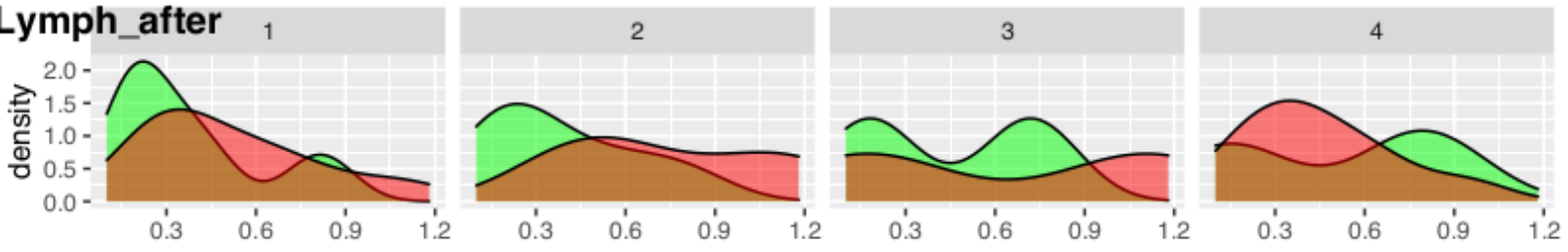

Figure 4

Density plots of the three biomarkers ( $\mathrm{PaO} 2$, Lymphocyte count and Lactate) before and after propensity score matching. Stratum 1 to 4 were displayed separately. 